\title{
Mental healthcare in Brunei Darussalam: recent developments in mental health services and mental health law
}

\author{
Hilda Ho
}

Head of Psychiatric Services, RIPAS Hospital, Bandar Seri Begawan Brunei Darussalam, Begawan, Brune Darussalam, Declaration of interest: Dr Hilda Ho is a consultant forensic psychiatrist. She is currently Head of Psychiatric Services, Ministry of of Pylth, Brunei Darussalam. The
Healn views expressed in this paper are her own and do not necessarily represent those held by the Ministry of Health.

\begin{abstract}
Mental health services and legislation in Brunei Darussalam have undergone a period of development and reform. This paper describes the challenges met, recent innovations and priority areas for the next 10 years.
\end{abstract}

Brunei Darussalam (population 406000) is a small country in South East Asia. It scores highly on economic, health and social indicators (United Nations, 2013) and is classified as a high-income economy (World Bank, 2014). Mental health services in Brunei started as a single ward in the old general hospital in the capital, Bandar Seri Begawan. In 1984, this was replaced by a bigger hospital, named Raja Isteri Pengiran Anak Saleha (RIPAS Hospital). Medical services are based in this and three other district hospitals, with large out-patient clinics. There is a growing network of primary health centres. Healthcare for citizens and permanent residents is virtually free of charge. Unlike in many other countries, there has never been a large asylum for those with a mental disorder. At the same time, there are no organisations or advocacy groups for mental illness. There is limited understanding of the range and complexity of mental disorders. Traditional and cultural beliefs predominate over a scientific understanding of mental disorders. Stigma and prejudice present a challenge.

\section{Cultural beliefs and attitudes to mental disorder}

Mental disorders are poorly understood. Stigma and prejudice against those with mental disorder are pervasive and discourage people from seeking treatment. Mental illness is often believed to be caused by spirit possession and black magic. All mental health problems are thrown into a single category, gila, loosely translated as 'crazy'. These people are identified by their observed abnormal behaviour rather than any proper understanding of the causes or features of mental disorders. Unsurprisingly, such conditions are associated with shame and rejection by society.

Relatives often turn to religious and spiritual healers first, and approach hospitals only when the afflicted person becomes violent. Thus many people suffer from a mental disorder for years before they are brought to the attention of health services. Perhaps for these reasons, there are no non-governmental organisations for mental illness, although groups for autistic disorders and children with intellectual disabilities have recently been formed. However, the mental health service receives some assistance from charitable organisations which provide support in terms of volunteers and resources for specific projects. The Department of Psychiatry at RIPAS Hospital runs a family education programme in a community rehabilitation centre in Bandar Seri Begawan, which aims to provide a place where the relatives and carers of people with mental disorders can learn, meet and find support.

\section{Service configuration}

Mental health services are all government run and are largely based in the Department of Psychiatry at RIPAS Hospital and in Suri Seri Begawan (SSB) Hospital in Kuala Belait town. A mental health country report on Brunei Darussalam has been published in this journal (Sabri \& Khan, 2008).

There has been a period of development since then. There are 32 designated psychiatric beds in the country (20 in RIPAS Hospital and 12 in SSB Hospital), but the ward in RIPAS Hospital is regularly filled over capacity. There are no subspecialty in-patient wards and so all patients requiring inpatient treatment are admitted to the same general wards.

It was clear that new mental health legislation was needed to replace the outdated 1929 Lunacy Act and work on this was started in 2011. Under the Lunacy Act, patients could be involuntarily admitted to hospital. This required a family member or police officer to approach a magistrates' court with an application. This did not require a medical practitioner's recommendation by law, which often caused considerable difficulty in clinical practice. While awaiting improved legislation, a system was introduced in RIPAS Hospital where patients' families are encouraged to take the patient to see a doctor and obtain a written medical opinion before making an application. With this, there has been some improvement in the management of involuntary admissions.

Community mental health teams have expanded. These teams serve each of the four geographical districts, and comprise two to four psychiatric nurses and sessional doctors. The focus of visits is on medication, monitoring of mental state and engaging the patients and their families in treatment. It is common for multiple generations to live together in the same household. There 
is a community child and adolescent mental health team, with three nurses supervised by a child and adolescent specialist in psychiatry. There are dayhospital facilities in each district, staffed by nurses, who are often shared with community team services. A community rehabilitation centre is fairly well established in Bandar Seri Begawan.

Referrals are received from primary care doctors or other medical practitioners. The general public can self-present to obtain an appointment, but are encouraged to see a primary care doctor first. There are busy general psychiatric clinics in each of the four district hospitals. In addition, psychiatric clinics have been established in some primary health centres in order to improve the accessibility of psychiatric care and to ease congestion in the hospital clinics.

Referrals for psychiatric reports are received from the police, courts and criminal justice systems. Mental health legislation dealing with offenders with a mental disorder is less well developed than in other modern jurisdictions. The 1951 Criminal Procedure Code addresses 'persons of unsound mind' but contains no definition of such persons. Offenders with a mental disorder requiring assessment and treatment in hospital are brought to general wards under police escort. Patients assessed as being too high a risk to place in the wards are treated in prison, though the prisons do not have medical wards. However, forensic psychiatric clinics have been established in the two national prisons and residential drug rehabilitation centre.

\section{Professional healthcare staff}

Human resources and service sustainability are significant challenges. The numbers of professionals working in the health services are presented in Table 1. There are six consultants or specialist psychiatrists working full time, two of whom were newly recruited at the end of 2013. There are eight full-time 'medical officers' or 'senior medical officers' in psychiatry. These are medical graduates with some psychiatric training. The majority of medical staff are foreign nationals who are employed on a 3-year contract.

There is a medical school which offers a preclinical undergraduate course. Students are sent overseas to partner institutions in order to complete their clinical training. In recent years, a 2-year foundation training scheme has been set up for returning medical graduates, similar to the UK system. There is an established vocational training scheme for primary care doctors. Both schemes offer 3- to 4-month rotations through psychiatry. There is no established postgraduate training scheme for psychiatry as a specialty. Promising local doctors are sent overseas to train, funded by the government. The Department of Psychiatry at RIPAS Hospital is exploring the opportunities for fellowship or exchange programmes with psychiatric training schemes abroad and is planning to start a higher training programme in partnership with an overseas institution.

There are 50 trained nurses working in mental health. Staff nurses are recruited into psychiatry with a basic general nursing qualification. They may apply to do a diploma in mental health nursing after working in the Department of Psychiatry at RIPAS Hospital or SSB Hospital. Some have the opportunity to be sent overseas or to the local university for further studies. Nurses are supplemented by mental health workers, nursing assistants and attendants.

There are three occupational therapists working in mental health. Psychologists are consulted from the general pool of psychologists in RIPAS Hospital or in the community clinics. There are 'medical social workers' or social officers working in the hospitals. Community welfare services exist but require much development. There are no formal training schemes for clinical psychologists, occupational therapists or social workers. There have been advances in multidisciplinary and multisectorial collaboration; however, this requires urgent development in order to provide fully holistic patient care.

\section{Innovation and commitment}

Despite these challenges, Brunei can be a rewarding place to work. In the past year, seclusion, nursing observations, rapid tranquillisation, control and restraint, admission and discharge, and incidentreporting protocols have been implemented on the psychiatric ward at RIPAS Hospital. These are now also being introduced in the psychiatric

\section{Table 1}

Numbers of health professionals working in mental health, audited in 2013

\begin{tabular}{|l|l|l|l|l|l|}
\hline $\begin{array}{l}\text { Health professionals working in mental health } \\
\text { services }\end{array}$ & $\begin{array}{l}\text { Total } \\
\text { number }\end{array}$ & $\begin{array}{l}\text { Number per 100000 } \\
\text { population }\end{array}$ & $\begin{array}{l}\text { Median rate per 100 000 } \\
\text { across the Western } \\
\text { Pacific Region area }\end{array}$ & $\begin{array}{l}\text { Median rate per 100000 } \\
\text { across the world }\end{array}$ & $\begin{array}{l}\text { Median rate per 100000 } \\
\text { across high-income } \\
\text { countries }\end{array}$ \\
\hline Consultant psychiatrists/specialists & 6 & 1.5 & 0.90 & 1.27 \\
\hline Other medical doctors & 8 & 2.0 & 0.81 & 0.33 \\
\hline Nurses (staff-nurse grade and above) & 50 & 12.5 & 7.70 & 4.95 \\
\hline Occupational therapists & 3 & 0.75 & 0.00 & 0.06 \\
\hline Clinical psychologists & 4 & 1.0 & 0.00 & 29.15 \\
\hline Social workers & 0.5 & 0.125 & 0.00 & 3.51 \\
\hline
\end{tabular}


ward in SSB Hospital. Formal training in control and restraint has been provided to all staff. There are plans to expand in-patient facilities over the next 2 years. Offenders with mental disorders in custodial institutions now have access to in-reach psychiatric treatment.

National delegates were in attendance at the 65th World Health Assembly, which endorsed the Comprehensive Mental Health Action Plan 20132020 (World Health Organization, 2013).

The relatively small scale of services in Brunei facilitates change and there is plenty of scope for innovation, with an eye on meeting targets set out by the World Health Organization, in particular the increase of service coverage and community-based holistic care, health promotion across multiple sectors and the introduction of modern mental health legislation.

The expansion of community mental health and rehabilitation services is a priority, in order to shift towards the integration of mental healthcare into non-specialised settings. Mental health clinics have been introduced in primary health centres and more are being planned, with a vision to integrate mental health clinics and rehabilitation/day care into all primary health centres. A new assistedliving unit in the community has been opened in order to provide long-term in-patients with a supported home. Primary care doctors have access to training for the management of common mental disorders and psychiatry is part of the syllabus in the vocational training scheme for primary care doctors. Multidisciplinary mental health teams are being developed with involvement from occupational therapists, psychologists and social workers. The National Health Systems Masterplan includes a strategy for mental healthcare at primary and secondary levels, as well as the establishment of a National Mental Health Institute as a centre for tertiary care, training and research.

To date, there has been little population-based research in mental health. The introduction of an electronic patient information management system in the hospitals and primary care centres in 2013 is an opportunity to start the collection of population-based data. Research and population data are required to inform a National Mental Health Plan to meet the needs of the population over the next decade.

Public education is important, to address stigma against mental disorders and to improve the acceptability of mental health services. The Ministry of Health has a rolling annual programme of mental health promotion forums which are used as a discussion platform for community groups such as village heads, school teachers and students, community welfare workers, community groups and interested individuals. Engaging with partner agencies, community leaders and policy makers can be a useful way to gain support.

In 2014 Brunei chaired and hosted the second meeting of the Association of South East Asian Nations (ASEAN) Mental Health Task Force, a group which works to improve mental healthcare in the region.

Perhaps the biggest body of work to date has been the preparation of new mental health legislation, the 2014 Mental Health Order. This essential legislation replaces the 1929 Lunacy Act and is designed to address the care, treatment, welfare and protection of people with a mental disorder. It has been the result of 3 years of stakeholder consultation and careful redrafting. A national stakeholder's road-show and training programme are underway to prepare for the implementation date of 1 November 2014. This order is unique in that although it is civil legislation, it is also compliant with the principles of Syariah law to ensure consistency across the country's two legal systems.

\section{Conclusion}

There is growing recognition of the importance of mental healthcare in Brunei. The establishment of sustainable, modern mental health services is a challenging task that requires innovation and commitment from ground to government level. Consistent leadership, innovation and human resource development are essential.

\section{References}

Sabri, R. \& Khan, A. (2008) Psychiatry in Brunei Darussalam. International Psychiatry, 5, 34-35.

United Nations (2013) World statistics pocketbook country profile: Brunei Darussalam. Available at http://unstats.un.org/unsd/ pocketbook/PDF/2013/brunei \% 20Darussalam.pdf (accessed September 2013).

World Bank (2014) Country and lending groups. Available at http:// data.worldbank.org/about/country-and-lending-groups\#High_ income (accessed January 2014).

World Health Organization (2011) Mental Health Atlas 2011. Available at http://whqlibdoc.who.int/ publications/2011/9799241564359_eng.pdf (accessed January 2014).

World Health Organization (2013) Comprehensive Mental Health Action Plan 2013-2020. Resolution WHA 66/8. Available at http://www.who.int/mental_health/publications/action_plan/en/ (accessed September 2013). 